Brazilian Journal of Microbiology (2010) 41: 1133-1141

ISSN 1517-8382

\title{
IMPROVEMENT OF PENICILLIN G ACYLASE EXPRESSION IN ESCHERICHIA COLI THROUGH UV INDUCED MUTATIONS
}

\author{
Rubina Arshad ${ }^{1}$, Shafqat Farooq ${ }^{2}$, Syed Shahid Ali
}

${ }^{1}$ Nuclear Institute for Agriculture and Biology (NIAB), Faisalabad, Pakistan; ${ }^{2}$ Pakistan Atomic Energy Commission, Islamabad, Pakistan; ${ }^{3}$ University of the Punjab, Lahore, Pakistan.

Submitted: May 09, 2009; Returned to authors for corrections: February 18, 2010; Approved: April 26, 2010.

\begin{abstract}
We used ultraviolet (UV) radiation to induce mutation in three locally isolated strains of Escherichia coli. Different dilutions of bacterial cultures were exposed to UV lamp of $254 \mathrm{~nm}$ wavelength for different time intervals at varied distances ranging from 5 to $210 \mathrm{sec}$ and 5 to $100 \mathrm{~cm}$. Viable colonies were screened for mutants with an increased production of penicillin G acylase (PGA) and a reduced production of $\beta$ lactamase, which are the desired properties of PGA producing industrial strains. A survival curve was made to get optimum exposure time and distance. The survival percentage for each exposure period was calculated and $1-5 \%$ survival was found useful for obtaining mutants with desired change. Screening for PGA and $\beta$-lactamase constitutive and/or deficient mutants was made by Serratia marcescens overlay test. A total of 100 survivors were selected of which $49 \%$ expressed PGA activity higher than the parent strain. Frequency of $\beta$-lactamase constitutive and deficient mutants was 48 and 52\%, respectively. The best hyper-producing mutant (BDCS-N-M74), with almost negligible expression of $\beta$-lactamase, exhibited three-fold (22.5 mg 6-APA h${ }^{-1} \mathrm{mg}^{-1}$ wet cells) increase in PGA activity compared with that in the parent strain (6.7 $\mathrm{mg} \mathrm{6}^{-\mathrm{APA} \mathrm{h}} \mathrm{mg}^{-1}$ wet cells). The results indicated the successful induction of UV mediated mutation in E. coli for PGA hyper-producing mutants lacking $\beta$-lactamase activity.
\end{abstract}

Key words: Escherichia coli, mutation, penicillin G acylase expression, UV irradiation.

\section{INTRODUCTION}

Penicillin G acylase (PGA) is an industrially important enzyme used for the production of 6-aminopenicillanic acid (6APA), which is a starting compound for the synthesis of $\beta$ lactam antibiotics (21). $\beta$-lactamases on the other hand, are microbial enzymes that convert $\beta$-lactam antibiotics into biologically inactive metabolites such as penicilloic acid and penicic acid (14). The coexistence of PGA and $\beta$-lactamases in wild bacterial strains is one of the major factors responsible to reduce the biosynthesis of 6-APA (7). Genetic and protein engineering techniques are used to manipulate $E$. coli to overcome this major limiting factor in acquiring high level of PGA production (10).

Strategies for hyper-production of PGA using recombinant DNA technology are well-documented $(8,10,15)$. Few reports

\footnotetext{
*Corresponding Author. Mailing address: Nuclear Institute for Agriculture and Biology (NIAB), P.O. Box 128, Jhang Road, Faisalabad-Pakistan..; Tel.: \# 0092 412654221 (30) Mobile: \# 00920300 7663009.; E-mail: arshadrubina@ hotmail.com
} 
are also available on mutagenesis in bacterial strains by UV radiation and/or $\quad N$-methyl- $N$ '-nitro- $N$-nitrosoguanidine (MNNG) for achieving the same objective $(12,16)$. Successive treatment with UV, gamma-irradiation and ethylmethane sulfonate has been used to obtain a Beijerinckia indica mutant producing $168 \%$ more penicillin V acylase (4). Site-directed mutagenesis is also conducted to investigate which residues and interactions influence the performance of PGA in the formation of $\beta$-lactam antibiotics $(1,3,19)$. However, none of these studies reported the UV induced mutants with completely lacking or reduced expression of $\beta$-lactamase. We previously reported that the treatment of $E$. coli cells with acridine orange (AO) could result in mutants with enhanced production of PGA and inactivation of $\beta$-lactamase (6). In the current study, we designed experiments to induce mutations through UV irradiation in different $E$. coli strains for enhancing their ability to produce PGA and to reduce and/or eliminate $\beta$-lactamase. As a pre-requisite, we standardized appropriate (i) culture conditions, (ii) exposure time and (iii) distance from UV lamp to the cells to be exposed. Our objective was to assess the potential of UV radiation to induce mutations for enhancing PGA production and to reduce/eliminate the activity of $\beta$ lactamase.

\section{MATERIALS AND METHODS}

\section{Bacterial cultures and serial dilutions}

Three wild-type E. coli strains BDCS-N-S21, BDCS-NW50 and BDCS-N-FMu10 (5) were used in this study. These strains were grown in Luria Bertani (LB) broth at $37^{\circ} \mathrm{C}$ with shaking at $150 \mathrm{rpm}$. Fresh overnight grown cultures $(40 \mathrm{ml})$ with a cell density of about $2 \times 10^{8}$ cells $\mathrm{ml}^{-1}\left(\mathrm{OD}_{600}=0.4\right)$ were chilled on ice for 5 to $10 \mathrm{~min}$ and were divided into 8 tubes each containing $5 \mathrm{ml}$ of culture. Culture from each tube was harvested by centrifugation for $5 \mathrm{~min}$ at 5000 to $6000 \mathrm{x} \mathrm{g}$. Pellets were re-suspended in an equal volume of $0.1 \mathrm{M} \mathrm{MgSO}_{4}$ and were placed on ice for 5 to $10 \mathrm{~min}$. For each exposure time, cell suspension was spread evenly on a sterilized petri plate.

\section{Irradiation of cultures and induction of mutations}

Miller's (18) protocol was modified for induction of mutation through UV irradiation. The plate containing cell suspensions was placed on an adjustable platform below a UV germicidal lamp $(254 \mathrm{~nm})$ fixed in a chamber. The UV irradiation was carried out by adjusting the distance between UV lamp and culture plate from 5 to $100 \mathrm{~cm}$ and exposure times from 5 to $210 \mathrm{sec}$. In original protocol (18), distance of $37 \mathrm{~cm}$ was fixed between UV lamp and culture plate.

Irradiated and control samples were immediately diluted serially at $4^{\circ} \mathrm{C}$. Three aliquots from a particular dilution were irradiated (as three replicates) for each UV dose. About $0.1 \mathrm{ml}$ each from these dilutions $\left(10^{-2}, 10^{-4}, 10^{-5}, 10^{-6}, 10^{-7}\right)$ was plated and viable colonies were counted after incubation made in dark at $37^{\circ} \mathrm{C}$ for $24 \mathrm{~h}$. The frequencies of viable cells $\left(\mathrm{CFU} \mathrm{ml}{ }^{-1}\right)$ in the total bacterial population were determined by comparing the number of colonies to the volume of sample plated and dilution used. Five dilutions were used in the present study whereas previously only three dilutions $\left(10^{-3}, 10^{-4}, 10^{-5}\right)$ were utilized for this purpose (18). The dilution giving the most suitable growth was selected.

\section{Growth and survival curves}

The irradiated and un-irradiated (control) cells taken from different dilutions, distance and exposure time were spread immediately on respective agar plates for determination of surviving fractions. After overnight incubation at $37^{\circ} \mathrm{C}$, the viable colonies were recorded and survival curves (semi-log) were constructed by plotting the log of the surviving fraction against the time of exposure. All these conditions were standardized using one bacterial strain BDCS-N-FMu10. These optimized conditions were used for analyzing mutations in three strains.

\section{Screening of mutants for $\beta$-lactamase and PGA expression}

The irradiated samples $(0.25 \mathrm{ml})$ were inoculated in $5 \mathrm{ml}$ of $\mathrm{LB}$ medium and incubated overnight at $37^{\circ} \mathrm{C}$ with aeration. About $0.1 \mathrm{ml}$ each of overnight culture from irradiated samples and un-irradiated control were plated on LB agar (to monitor 
viable cells) and on nutrient agar (NA) supplemented with $1 \%$ starch (to test for $\beta$-lactamase positive and negative mutants). Plates were incubated overnight at $37^{\circ} \mathrm{C}$ and viable cells in each culture plates were calculated. After scoring viable cells, culture plates with $1 \%$ starch were stained with penicillin solution (20 mg of penicillin $\mathrm{G} \mathrm{ml}^{-1}$ ) containing $0.1 \mathrm{M}$ iodine in $0.4 \mathrm{M} \mathrm{KI}$ (6). $\beta$-lactamase deficient survivor colonies were screened for evaluation of PGA expression using $S$. marcescens overlay plate assay and spectrophotometric PDAB method (6). One unit of PGA activity was defined as the amount of 6-APA produced $\mathrm{h}^{-1} \mathrm{mg}^{-1}$ wet cells under assay conditions.

\section{RESULTS}

\section{Serial dilutions v/s exposure time: effect on bacterial} survival

The results of effect of UV $(254 \mathrm{~nm})$ irradiation on survival of three $E$. coli strains (BDCS-N-S21, BDCS-N-W50 and BDCS-N-FMu10) are shown in Fig. 1. Exposure of strains in the dilution of $10^{-2}$ to $10^{-5}$ to UV irradiation for 5 to $120 \mathrm{sec}$ appeared to have no significant effect on bacterial survival even after $45 \mathrm{sec}$ of exposure. It appeared that $10^{-2}$ to $10^{-6}$ dilutions of control (un-irradiated) and irradiated samples produced a large number of bacterial colonies which could not be counted accurately. However, in $10^{-7}$ dilution of both irradiated and un-irradiated samples, well-spread colonies were observed which could be counted easily. Increasing dilution to and beyond $10^{-6}$ significantly reduced bacterial survival even after $30 \mathrm{sec}$ of exposure (Fig. 1A-C). This reduction was $60 \%$ in BDCS-N-W50 and 75\% in BDCS-N-S21 and BDCS-NFMu10 when exposed in the dilution of $10^{-7}$. Further increase in exposure time to $120 \mathrm{sec}$, reduced progressively the percentage of survival in all the strains with minimum $(0.4 \%)$ observed in BDCS-N-S21 and BDCS-N-FMu10 (Fig. 1A and 1C) while the maximum survival $(0.6 \%)$ was observed in BDCS-N-W50 in dilution $10^{-7}$ (Fig. 1B). Increase in exposure time beyond $120 \mathrm{sec}$ resulted in complete killing of the cells (data not shown). The most suitable dilution for mutation study was chosen after this preliminary test for percentage of survival. Since bacterial survival adequate to detect mutations was observed in $10^{-7}$ dilution exposed for 30-90 sec, these conditions (exposure time and $10^{-7}$ dilution) were therefore selected for mutation frequency analysis.

(A)

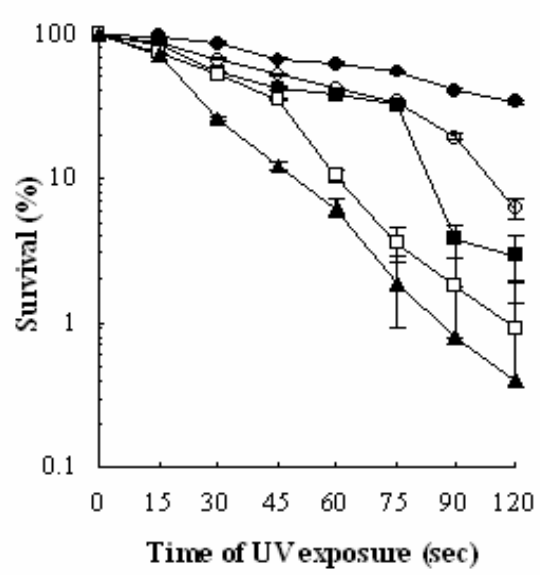

(B)

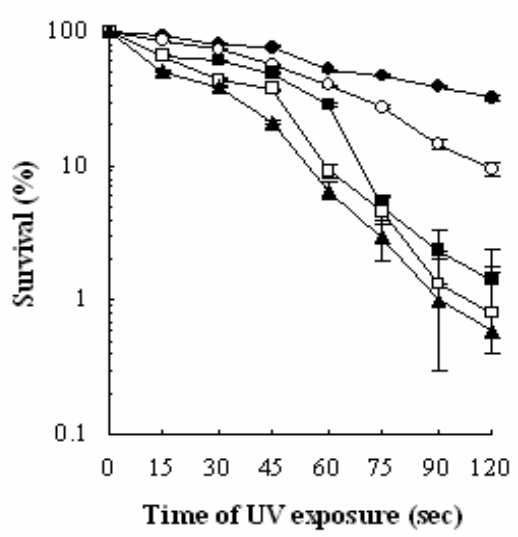

(C)

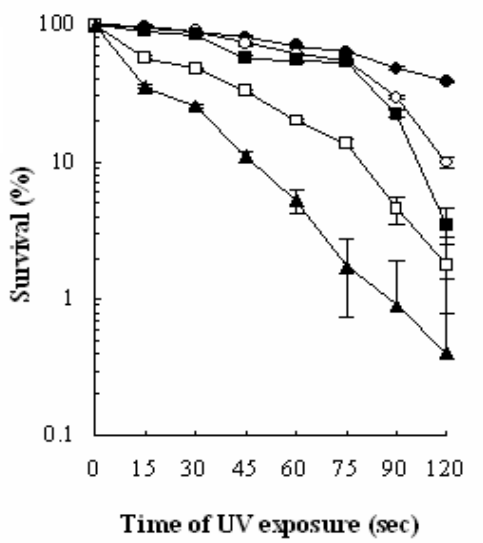

Figure 1. Comparison of percentage of survival of bacterial strains (A) BDCS-N-S21, (B) BDCS-N-W50 and (C) BDCS-N-FMu10 in various dilutions $10^{-2}(\bullet), 10^{-4}(\circ), 10^{-5}(\mathbf{a}), 10^{-6}(\square)$ and $10^{-7}$ $(\boldsymbol{\Delta})$ after different times of UV exposure. 
Interaction of dilutions with exposure times: effect on bacterial survival

The percentage of survivors in all the strains decreased with the increase in exposure to UV irradiation however, the pattern of reduction in survival was different for the three strains (Fig. 2). The survival reduction in BDCS-N-S21 growing at $10^{-7}$ was the lowest $(29 \%)$ and in BDCS-N-FMu10 the highest (65\%) after $15 \mathrm{sec}$ of exposure. Further increase in exposure time from 30 to $45 \mathrm{sec}$ significantly widened the difference between the three strains. Overall, the highest survival percentage after every exposure time was observed in BDCS-N-W50.

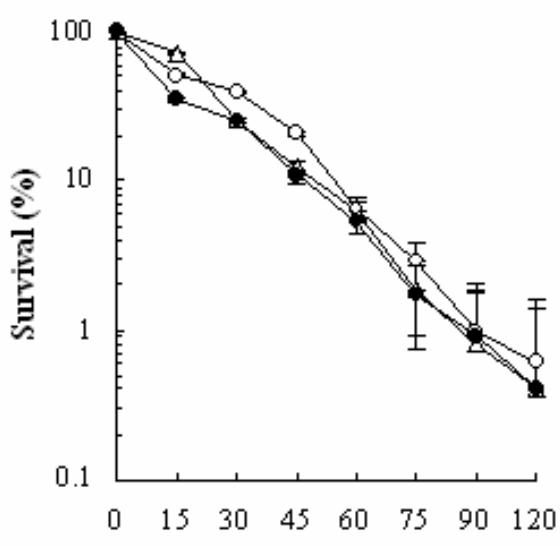

Time of UV exposure (sec)

Figure 2. Effect of UV exposure given to three bacterial strains BDCS-N-S21 ( $\Delta$ ), BDCS-N-W50 (०) and BDCS-N-FMu10 (•) in $10^{-7}$ dilution.

\section{Effect of distance from UV source on bacterial survival}

Figure 3 shows the survival rate of three bacterial strains (BDCS-N-S21, BDCS-N-W50 and BDCS-N-FMu10) in $10^{-7}$ dilution after exposed for $75 \mathrm{sec}$ from various distances (5 to $100 \mathrm{~cm})$. Increase of the exposure distance of the strains to UV from 5 to $10 \mathrm{~cm}$, accounted for a sharp increase in survival percentage ( 0.1 to $2.9 \%)$. The bacterial survival progressively increased up to $19 \%$ when the distance was increased from 20 to $50 \mathrm{~cm}$. Further increase in distance to $50 \mathrm{~cm}$ resulted in more or less $40 \%$ survival. Maximum percentage of survivor colonies was obtained at greater distance and a similar trend was observed in all the strains for different exposure times (data not shown). Hence, UV exposure at a distance of $10 \mathrm{~cm}$ from the lamp was selected to analyze mutation frequency.

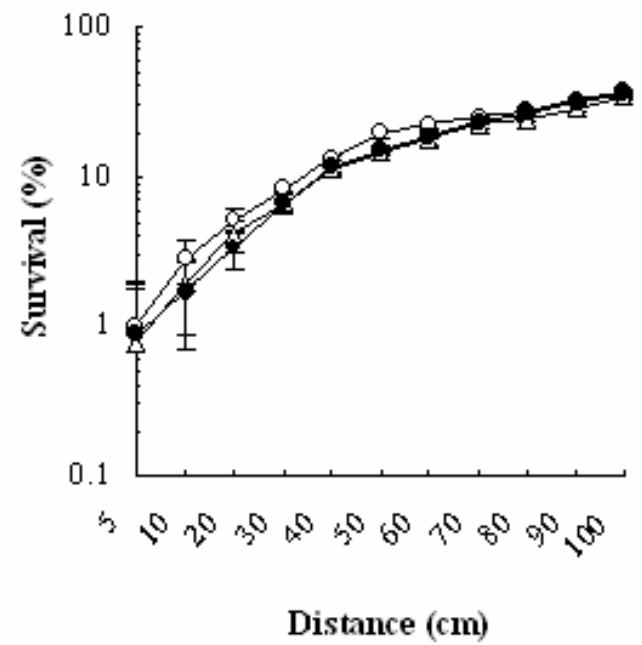

Figure 3. Effect of UV exposure given from various distances of UV irradiation on percentage of survival of three bacterial strains BDCS-N-S21 ( $\Delta)$, BDCS-N-W50 (०) and BDCS-NFMu10 (•) in $10^{-7}$ dilution.

\section{Selection of mutants from UV irradiated population}

Table 1 exhibits frequency distribution of PGA and $\beta$ lactamase positive and negative mutants obtained from three strains. A total of 100 survivor colonies were selected from three strains. Our data showed that $52 \%$ survivors were $\beta$ lactamase deficient (negative) whereas $89 \%$ were PGA constitutive (positive). Among these, 49 expressed higher level of PGA expression than that of the respective parent while 40 mutants contained less PGA activity than their parent (Table 1). The frequency of $\beta$-lactamase negative mutants in BDCSN-S21, BDCS-N-W50 and BDCS-N-FMu10 was 13 (43.3\%), $29(72.5 \%)$ and $10(33.3 \%)$, respectively while those of $\beta$ lactamase positive mutants, with less activity than the parent, was $17(56.7 \%), 7(17.5 \%)$ and 20 (66.7\%), respectively. Only four $(10 \%)$ mutants in BDCS-N-W50 had higher $\beta$-lactamase level than the parent. Similarly, frequency of mutants in 
BDCS-N-S21, BDCS-N-W50 and BDCS-N-FMu10 expressing higher PGA activity than that of the parents was $17(56.7 \%)$, $19(47.5 \%)$ and $13(43.3 \%)$, respectively, while those expressing less than the parents remained 11 (36.7\%), 20
$(50 \%)$ and 9 (30\%), respectively. Overall, BDCS-N-W50 produced the highest number (29) of $\beta$-lactamase negative as well as the highest number (19) of mutants that exhibited PGA activity higher than the parent (Table 1).

Table 1. Percentage frequency of mutants for penicillin G acylase (PGA) and $\beta$-lactamase ( $\beta$-lact) activity after UV irradiation

\begin{tabular}{|c|c|c|c|c|}
\hline \multirow[t]{2}{*}{ Enzyme } & \multicolumn{4}{|c|}{$\begin{array}{c}\text { Strains } \\
\text { No. of mutants }(\%)\end{array}$} \\
\hline & BDCS-N-S21 & BDCS-N-W50 & BDCS-N-FMu10 & Total \\
\hline $\mathrm{PGA}^{+>}$ & $17(56.7)^{* a}$ & $19(47.5)^{b}$ & $13(43.3)^{\mathrm{c}}$ & $49(49)^{b}$ \\
\hline $\mathrm{PGA}^{+<}$ & $11(36.7)^{b}$ & $20(50)^{\mathrm{a}}$ & $9(30)^{\mathrm{c}}$ & $40(40)^{\mathrm{d}}$ \\
\hline $\mathrm{PGA}^{-}$ & $2(6.7)^{b}$ & $1(2.5)^{\mathrm{c}}$ & $8(26.7)^{\mathrm{a}}$ & $11(11)^{\mathrm{e}}$ \\
\hline$\beta$-lact ${ }^{+>}$ & $0(0)^{b}$ & $4(10)^{\mathrm{a}}$ & $0(0)^{b}$ & $4(4)^{\mathrm{f}}$ \\
\hline$\beta-$ lact $^{+<}$ & $17(56.7)^{\mathrm{b}}$ & $7(17.5)^{c}$ & $20(66.7)^{\mathrm{a}}$ & $44(44)^{\mathrm{c}}$ \\
\hline$\beta$-lact ${ }^{-}$ & $13(43.3)^{b}$ & $29(72.5)^{\mathrm{a}}$ & $10(33.3)^{\mathrm{c}}$ & $52(52)^{\mathrm{a}}$ \\
\hline
\end{tabular}

+> greater than parent; +< less than parent; - Nil; Values outside the parenthesis correspond to the number of mutants and those inside correspond to the percentages; "Numbers with different letters are significantly different at $P<0.05$ with Duncan's Multiple Range (DMR) test.

\section{Effect of time and distance of exposure on the frequency of} mutants for PGA and $\beta$-lactamase expression

The mutation frequency of PGA and $\beta$-lactamase constitutive/deficient mutants analyzed at a set distance of 10 $\mathrm{cm}$ for varying exposure times is shown in Fig. 4A-C. The percentage of survivors decreased consistently for UV exposure from a distance of less than $5 \mathrm{~cm}$. The highest frequency of PGA hyper producing mutants in BDCS-N-S21 (four) and BDCS-N-W50 (eight) was retained after $45 \mathrm{sec}$ of exposure (Figure 4A and 4B). In BDCS-N-W50, seven out of eight PGA hyper-producing mutants induced after $45 \mathrm{sec}$ of exposure, exhibited negligible $\beta$-lactamase expression (Fig. 4B). In BDCS-N-FMu10, the highest number of mutants (four) with increased PGA activity was recorded after $30 \mathrm{sec}$ of exposure. Among these, two mutants expressed negligible $\beta$ lactamase activity whereas the remaining two displayed less $\beta$ lactamase activity than the parent (Fig. 4C). Overall, four mutants obtained from BDCS-N-FMu10 expressed reduced $\beta$ - lactamase activity at UV exposure of 30 and $45 \mathrm{sec}$ and three at 60 to $120 \mathrm{sec}$. In BDCS-N-W50, a total of four mutants displayed $\beta$-lactamase activity higher than the parent at UV exposure of 15, 60, 75 and $120 \mathrm{sec}$. However, at varying times of exposure, none of the mutants in BDCS-N-FMu10 and BDCS-N-S21 manifested higher $\beta$-lactamase level than their parents.

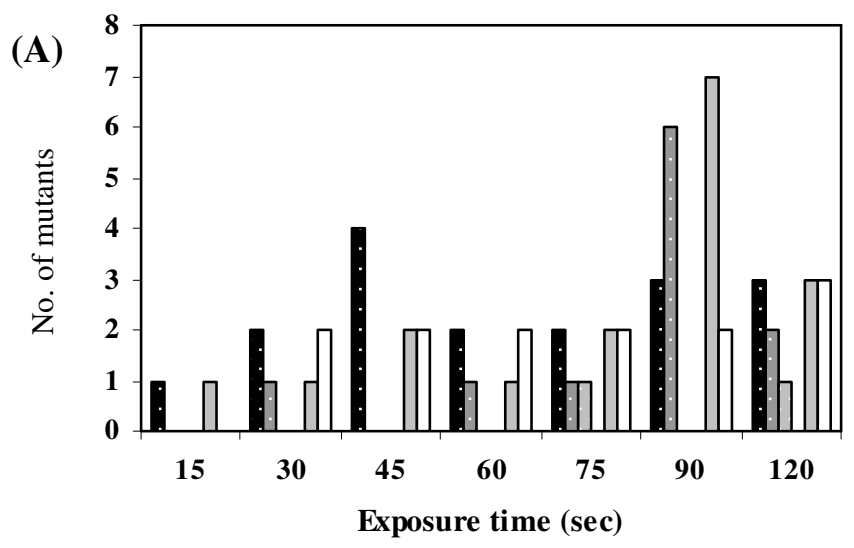


(B)

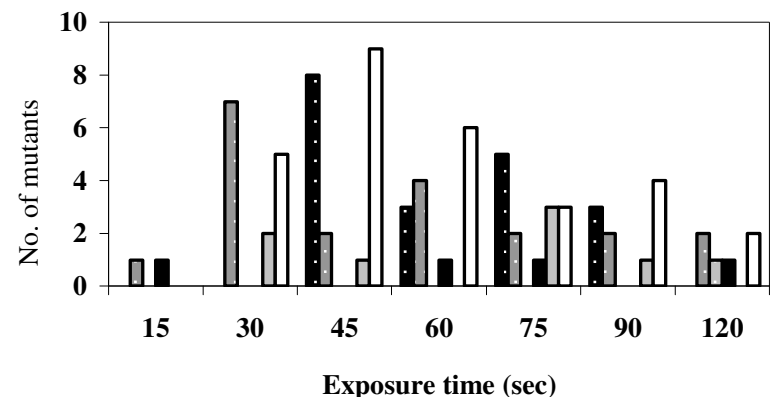

(C)

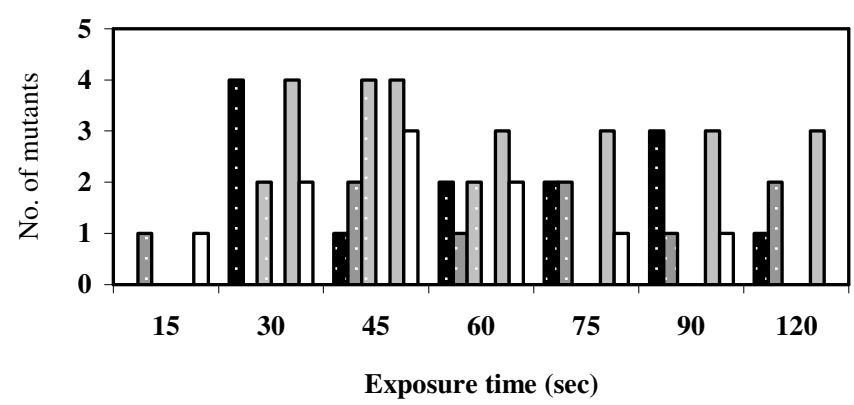

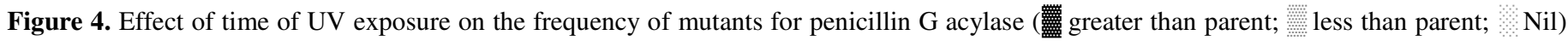
and $\beta$-lactamase $\square$ greater than parent; less than parent; $\square$ Nil) activity; (A) BDCS-N-S21, (B) BDCS-N-W50, (C) BDCS-N-FMu10 (UV lamp was set at $10 \mathrm{~cm}$ from cells).

\section{Effect of UV on PGA and $\beta$-lactamase expression}

The induced mutants obtained from the three strains produced considerable amounts of 6-APA with negligible expression of $\beta$-lactamase (Table 2). One-way ANOVA revealed a highly significant difference among mutants and parents $\left(\mathrm{F}_{21,44}=1464.1 ; P<0.05\right)$. Duncan's Multiple Range (DMR) Test $(P<0.05)$ indicated that mean PGA expression level was significantly higher in two mutants BDCS-N-M71 and BDCS-N-M74 obtained from BDCS-N-FMu10 and one mutant BDCS-N-M20 obtained from BDCS-N-S21 than their parents. These hyper-producing mutants displayed more than three-fold increase in PGA expression. The best hyperproducing mutant (BDCS-N-M74), with almost negligible expression of $\beta$-lactamase produced $22.5 \mathrm{mg} 6-\mathrm{APA} \mathrm{h}{ }^{-1} \mathrm{mg}^{-1}$ wet cells compared to the parent strain BDCS-N-FMu10 that produced $6.7 \mathrm{mg} 6$-APA h${ }^{-1} \mathrm{mg}^{-1}$ wet cells.

\section{DISCUSSION}

Ultraviolet (UV) radiation is one of the simplest and most convenient ways to induce mutations in bacteria (23) and is used for enhanced ethanol production (20), induction of alcohol tolerance in yeast (22), improvement in clavulanic acid production in Streptomyces clavuligerus (17) and bioinsecticides production in Bacillus thuringenesis (13). The catalytic efficiency and substrate specificity of penicillin acylase producing bacterial strains have also been improved through UV radiations (12). These mutations result in changes in the production of microbial metabolites and enzymes. More commonly the mutations result in death, so increased amounts of UV radiation most likely correspond to increased cell death (24). In the current study, we optimized bacterial culture dilutions, UV exposure distance and time for induction of mutation. Our results reflected significant variations among three strains with respect to their survival at different dilutions, UV exposure distance and time. In most of the cases, $10^{-7}$ dilution and exposure time of 30-90 sec that reduced bacterial survival to $<1 \%$ was found suitable for the selection of mutants exhibiting enhanced PGA production with reduced/eliminated $\beta$-lactamase expression. A survival rate of 1 to $5 \%$ is considered optimum for screening of mutants (11) however, for UV mutagenesis a survival rate of 0.1 to $1 \%$ is often used because of its low mutagenic efficiency (18). A low survival $(0.8 \%)$ is achieved by exposing bacterial cells in $10^{-3}$ dilution at a distance of $37 \mathrm{~cm}$ for $75 \mathrm{sec}$ (18). We obtained this survival rate $(<1 \%)$ in $10^{-7}$ dilution by UV exposure for $90 \mathrm{sec}$ from a distance of $10 \mathrm{~cm}$. This exposure time and dilution not only resulted in the death of the cells but also induced mutation of variable frequency depending upon the strain. Our results showed that the exposure time is directly related to the distance between the sample and the UV lamp. Moreover, the rate of survival depends on the distance and time of UV exposure. Thus, the survival rate decreased with increasing distance from the UV lamp and required somewhat longer exposure to UV. 
Table 2. Relative penicillin $G$ acylase and $\beta$-lactamase activities of parent and mutant strains

\begin{tabular}{|c|c|c|c|c|}
\hline \multirow{3}{*}{$\begin{array}{l}\text { Parent strain } \\
\text { E. coli }\end{array}$} & \multirow[t]{3}{*}{ Mutant \# } & \multicolumn{3}{|c|}{ Enzyme activity } \\
\hline & & \multicolumn{2}{|c|}{ Penicillin $\mathbf{G}$ acylase } & \multirow{2}{*}{$\begin{array}{c}\beta \text {-lactamase } \\
\text { Zone around } \\
\text { colony (status) }\end{array}$} \\
\hline & & $\begin{array}{l}\text { Inhibition zone } \\
\text { diameter }(\mathrm{mm})\end{array}$ & $\begin{array}{l}\text { mg } 6 \text {-APA } \mathrm{h}^{-1} \mathrm{mg}^{-1} \text { wet cells } \\
\text { Mean activity } \pm \text { S.D. }\end{array}$ & \\
\hline \multirow[t]{11}{*}{ BDCS-N-S21 } & BDCS-N- & 15 & $6.5 * \mathrm{r} \pm 0.1$ & White $(+)$ \\
\hline & M10 & 25 & $18.2 \mathrm{e} \pm 0.26$ & Nil (-) \\
\hline & M11 & 22 & $14.0 \mathrm{j} \pm 0.17$ & Nil (-) \\
\hline & M15 & 26 & $18.0 \mathrm{e} \pm 0.17$ & Nil (-) \\
\hline & M17 & 25 & $17.5 f \pm 0.2$ & Nil (-) \\
\hline & M18 & 26 & $18.9 \mathrm{~d} \pm 0.2$ & Nil (-) \\
\hline & M20 & 28 & $21.6 b \pm 0.26$ & Nil (-) \\
\hline & M22 & 22 & $12.6 \mathrm{k} \pm 0.17$ & Nil (-) \\
\hline & M25 & 23 & $15.0 \mathrm{i} \pm 0.2$ & Nil (-) \\
\hline & M26 & 23 & $15.5 \mathrm{~h} \pm 0.2$ & Nil (-) \\
\hline & M28 & 19 & $8.80 \pm 0.3$ & Nil (-) \\
\hline \multirow[t]{6}{*}{ BDCS-N-W50 } & & 16 & $6.3 r \pm 0.17$ & White (+) \\
\hline & M41 & 18 & $7.7 p \pm 0.26$ & Nil (-) \\
\hline & M51 & 18 & $7.2 q \pm 0.17$ & Nil (-) \\
\hline & M59 & 20 & $9.4 n \pm 0.36$ & Nil (-) \\
\hline & M66 & 21 & $10.3 \mathrm{~m} \pm 0.26$ & Nil (-) \\
\hline & M70 & 22 & $11.21 \pm 0.2$ & Nil (-) \\
\hline \multirow[t]{5}{*}{ BDCS-N-FMu10 } & & 16 & $6.7 r \pm 0.26$ & White (+) \\
\hline & M71 & 26 & $19.3 c \pm 0.35$ & Nil (-) \\
\hline & M74 & 29 & $22.5 a \pm 0.17$ & Nil (-) \\
\hline & M75 & 24 & $17.0 \mathrm{~g} \pm 0.26$ & Nil (-) \\
\hline & M83 & 21 & $9.5 n \pm 0.3$ & Nil (-) \\
\hline $\begin{array}{l}\text { One-way analysis of } \\
\text { variance (ANOVA) }\end{array}$ & & & $\begin{array}{c}\mathrm{F}=1464.1 * * * \\
\text { d.f. }=21,44 \\
P<0.05\end{array}$ & \\
\hline
\end{tabular}
experiments for each strain; *Means with different letters are significantly different with Duncan's Multiple Range (DMR) test at $P<0.05$.

The highest number of PGA hyper-producing mutants (eight) with almost negligible $\beta$-lactamase expression was derived from BDCS-N-W50 by UV exposure for a period of 45 sec. Probably, this strain was more amenable to mutation or the UV dose used to induce mutation was more appropriate for this strain than for others. Though the remaining two strains i.e., BDCS-N-FMu10 and BDCS-N-S21 were also responsive to $\mathrm{UV}$, a comparatively low number of promising mutants (four each) was obtained from these strains by an exposure of 30-45 sec. This indicated that every strain reacts differently to UV and requires specific conditions for inducing desired mutation. When a DNA damaging and mutagenic agent like UV light is experimentally used as a selective factor, natural resistance of bacteria to this agent is normally increased through processes of mutation and selection (2). Therefore, different strains give rise to different grades of UV resistance and consequently the mutation frequency. Failure to detect mutations from $10^{-2}$ to $10^{-5}$ dilutions could be due to mat like growth of bacterial cells in which shielding effect might have masked the frequency of surviving cells which in turn made the detection of mutated colonies difficult (9). Thus our work suggests that the conditions optimized to induce mutation in one strain may not work well for other strains and vary considerably depending upon the specific objective to be achieved.

It appeared that UV radiation induced mutation in the DNA of E. coli strains and caused a certain percentage of the cells to die. It was also clear that the number of survivors decreased as the amount of radiation increased. Moreover, it was interesting to know that most of these survivors were capable of expressing higher PGA levels than their parent. The 
general spectrum of mutations showed the highest number of mutants lacking $\beta$-lactamase activity with enhanced PGA expression while the strain specific spectrum showed the highest number of required mutants in BDCS-N-W50. A twofold increase in PGA expression with reduced or negligible $\beta$ lactamase activity has previously been reported in a mutant strain (BDCS-N-M36) derived from the AO-treated E. coli strain (6). In the present study, three mutants displayed threefold increase in PGA expression. Among these, the best PGA hyper-producing mutant (BDCS-N-M74), with almost negligible expression of $\beta$-lactamase, exhibited more than three-fold (22.5 mg 6-APA h${ }^{-1} \mathrm{mg}^{-1}$ wet cells) increase in PGA expression compared to the parent strain $\left(6.7 \mathrm{mg} 6-\mathrm{APA} \mathrm{h}^{-1}\right.$ $\mathrm{mg}^{-1}$ wet cells). To the best of our knowledge, this is the first report describing a novel aspect of the UV mediated induction of mutation in E. coli which resulted into the changes in the expression levels of PGA and $\beta$-lactamase. This study therefore, confirmed that (i) despite having low mutagenic efficiency, UV radiation can be used to generate $E$. coli mutants with increased PGA and reduced $\beta$-lactamase expression (with respect to the parent); (ii) the level of improvement achieved presently can further be enhanced using some other strains amenable to mutation induction.

\section{REFERENCES}

1. Abian, O.; Grazu, V.; Hermoso, J.; Gonzalez, R.; Garcia, J.L.; Fernandez-Lafuente, R.; Guisan, J.M. (2004). Stabilization of penicillin $\mathrm{G}$ acylase from Escherichia coli: site-directed mutagenesis of the protein surface to increase multipoint covalent attachment. Appl. Environ. Microbiol. 70, 1249-1251.

2. Alcantara-Diaz, D. ; Brena-Valle, M. ; Serment-Guerrero, J. (2004). Divergent adaptation of Escherichia coli to cyclic ultraviolet light exposures. Mutagenesis. 19, 349-354.

3. Alkema, W.B.L.; Hensgens, C.M.H.; Kroezinga, E.H.; de Vries, E.; Floris, R.; van der Laan, J.M.; Dijkstra, B.W.; Janssen, D.B. (2000). Characterization of the $\beta$-lactam binding site of penicillin acylase of Escherichia coli by structural and site-directed mutagenesis studies. Protein Engineering. 13, 857-863.

4. Ambedkar, S.S.; Deshpande, B.S.; Sudhakaran, V.K.; Shewale, J.G. (1991). Beijerinckia indica var. penicillanicum penicillin V acylase: enhanced enzyme production by catabolite repression-resistant mutant and effect of solvents on enzyme activity. J. Ind. Microbiol. 7, 209-214.

5. Arshad, R.; Farooq, S.; Ali, S.S. (2006). Characterization and documentation of bacterial diversity collected from various local habitats-1. Diversity in Escherichia coli. Pak. J. Bot. 38, 791-797.

6. Arshad, R.; Farooq, S.; Iqbal, N.; Ali, S.S. (2006). Mutagenic effect of acridine orange on the expression of penicillin $\mathrm{G}$ acylase and $\beta$-lactamase in Escherichia coli. Lett. Appl. Microbiol. 42, 94-101.

7. Arshad, R.; Saba, M. (2001). Studies on coexistence of penicillin G acylase and betalactamase in Escherichia coli. Pak. J. Microbiol. 1, 1318.

8. Chandel, A.K.; Rao, L.V.; Narasu, M.L.; Singh, O.V. (2008). Review: The realm of penicillin $\mathrm{G}$ acylase in $\beta$-lactam antibiotics. Enzyme Microb. Technol. 42, 199-207.

9. Carlton, B.C.; Brown, B.J. (1981). Gene Mutation. In: Gerhard, P. (ed). Manual of Methods for General Bacteriology. ASM Press, Washington, D.C., p. 222-242.

10. Chou, C.P.; Lin, W.-J.; Kuo, B.-Y., Yu, C.-C. (2000). Genetic strategies to enhance penicillin acylase production in Escherichia coli. Enzyme Microb. Technol. 27, 766-773.

11. Fantini, A.A. (1975). Strain Development. In: Hash, J.H. (ed). Antibiotics, Methods in Enzymology. Academic Press, New York, San Francisco, London, vol. 43, p. 24-41.

12. Forney, L.J.; Wong, D.C.L. (1989). Alteration of the catalytic efficiency of penicillin amidase from Escherichia coli. Appl. Environ. Microbiol. $55,2556-2560$.

13. Ghribi, D.; Zouari, N.; Jaoua, S. (2004). Improvement of bioinsecticides production through mutagenesis of Bacillus thuringenesis by u.v. and nitrous acid affecting metabolic pathways and/or delta-endotoxin synthesis. J. Appl. Microbiol. 97, 336-346.

14. Ghuysen, J.M. (1991). Serine betalactamases and penicillin binding proteins (Review). Annu. Rev. Microbiol. 45, 37-67.

15. Ignatova, Z.; Mahsunah, A.; Georgieva, M.; Kasche, V. (2003). Improvement of posttranslational bottlenecks in the production of penicillin amidase in recombinant Esherichia coli strains. Appl. Environ. Microbiol. 69, 1237-1245.

16. Kochetkova, E.F.; Bartoshevich, I.E.; Romanova, N.B.; Kuranina, O.G. (1986). Induced mutagenesis in Escherichia coli - a producer of penicillin acylase. Antibiot. Med. Biotekhnol. 31, 655-658.

17. Lee, S.D.; Park, S.W.; Oh, K.K.; Hong, S.-I.; Kim, S.W. (2002). Improvement for the production of clavulanic acid by mutant Streptomyces clavuligerus. Lett. Appl. Microbiol. 34, 370-375.

18. Miller, J.H. (1992). A Short Course in Bacterial Genetics. A laboratory Manual and Handbook for E. coli and Related Bacteria. Cold Spring Harbor Laboratory Press, Cold Spring Harbor, p. 150-156.

19. Morillas, M.; McVey, C.E.; Brannigan, J.A.; Ladurner, A.G.; Forney, L.J.; Virden, R. (2003). Mutations of penicillin acylase residue B71 extend substrate specificity by decreasing steric constraints for substrate binding. Biochem J. 371, 143-150.

20. Neelam, A.; Amarjit, S. (1991). Ethanol production by thermotolerant 
yeast and its UV resistant mutants. Acta Microbiol. Pol. 40, 171-175.

21. Shewale, J.G.; Deshpande, B.S.; Sudhakaran, V.K.; Ambedkar, S.S (1990). Penicillin acylases. Applications and potentials. Process Biochem. 25, 97-103.

22. Ünaldi, M.N.; Arikan, B.; Coral, G. (2002). Isolation of alcohol tolerant, osmotolerant and thermotolerant yeast strains and improvement of their alcohol tolerance by UV mutagenesis. Acta Microbiol. Pol. 51, 115-120.
23. Witkin, E.M. (1989). Ultraviolet mutagenesis and the SOS response in Escherichia coli. A personal perspective. Environ. Mol. Mutagenesis. 14 (sup. 6), 13-34.

24. Ying-Hsiu, L.; Cheng, A.; Wang, T.V. (1998). Involvement of recF, recO, and recR Genes in UV-Radiation Mutagenesis of Escherichia coli. J. Bacteriol. 180, 1766-1770. 